The Effect of Crossmodal Congruency Between Ambient Scent and the Store Environment on Consumer Reactions: An Abstract

Peer-reviewed author version

ADAMS, Carmen \& DOUCE, Lieve (2017) The Effect of Crossmodal Congruency Between Ambient Scent and the Store Environment on Consumer Reactions: An Abstract. In: Stieler, M. (Ed.). Creating Marketing Magic and Innovative Future Marketing Trends. Developments in Marketing Science: Proceedings of the Academy of Marketing Science, p. 913-914..

DOI: 10.1007/978-3-319-45596-9_169

Handle: http://hdl.handle.net/1942/21973 


\title{
THE EFFECT OF CROSSMODAL CONGRUENCY BETWEEN AMBIENT SCENT AND THE STORE ENVIRONMENT ON CONSUMER REACTIONS
}

\author{
Adams Carmen, Hasselt University, Belgium, carmen.adams@uhasselt.be \\ Doucé Lieve, Hasselt University, Belgium, lieve.douce@uhasselt.be
}

\begin{abstract}
The most important dimensions of an ambient scent when selecting this scent to be diffused in the store environment are its pleasantness and its congruity with the object (e.g., product or store) under investigation (Doucé et al., 2013). In this study we examine the importance of the congruency of the ambient scent with the crossmodal correspondences elicited by the store environment. A crossmodal correspondence refers to the tendency of one sensory modality to be matched with another sensory modality (Spence, 2012). The presence of a sensory cue in the store environment (e.g., the colours used) might trigger an expectation with respect to, for instance, the tactile sense (e.g., expected temperature). We propose that if the ambient scent triggers the same expectations as the store environment then the ambient scent and the store environment are crossmodally congruent. Furthermore, we state that diffusing a crossmodally congruent ambient scent in the store environment will lead to more positive effects compared to the use of a crossmodally incongruent ambient scent.
\end{abstract}

In order to measure the crossmodal correspondences elicited by the store and the ambient scent, a crossmodal correspondences index was developed (i.e., 11 bi-polar items based upon Crisinel, Jones, \& Spence, 2012). The absolute difference between the scores the store would receive and the scores the scent would receive on these 11 items (e.g., loud versus quiet) can then be averaged and result in a crossmodal congruency score between scent and store.

Three pretests were conducted: (1) to determine the crossmodal correspondences elicited by the store (i.e., a store selling cooking materials) by use of the crossmodal correspondence index, (2) to find two pleasant ambient scents of which one has the lowest possible crossmodal congruency score and one which has the highest possible score, and (3) to determine if the chosen scents are congruent with the products.

In the main study there were three conditions: a) no ambient scent, b) a crossmodally congruent ambient scent (i.e., Apple Pie) and c) a crossmodally incongruent ambient scent (i.e., Coffee). Results showed that the presence of a pleasant and product congruent ambient scent, whether or not crossmodally congruent with the store environment, has a positive influence on pleasure experienced in the store, store environment evaluation, and store evaluation compared to the absence of an ambient scent. This result indicates that crossmodal congruency does not necessarily lead to more positive effects. However, only an ambient scent that is crossmodally congruent has a positive effect on word-of-mouth and approach behaviour compared to the no scent condition. Moreover, a crossmodally congruent ambient scent also has a positive influence on approach behaviour compared to a crossmodally incongruent ambient scent. Thus, our results reveal that the use of a pleasant, product congruent and crossmodally congruent ambient scent holds some benefits.

The crossmodal correspondence index and crossmodal congruency score presented in this paper are fairly new concepts and are - in this study - based upon 11 items. Due to the effects that were found in this study, the further development of the crossmodal correspondence index and crossmodal congruency score is advised and recommended. 